\title{
The role of nonmuscle myosin II in polydrug memories and memory reconsolidation
}

\author{
Sherri B. Briggs, ${ }^{1,2}$ Madalyn Hafenbreidel,, ${ }^{1,2}$ Erica J. Young, ${ }^{1,2}$ Gavin Rumbaugh, ${ }^{2}$ \\ and Courtney A. Miller ${ }^{1,2}$ \\ ${ }^{1}$ Department of Molecular Medicine; ${ }^{2}$ Department of Neuroscience, The Scripps Research Institute, Jupiter, Florida 33458, USA
}

\begin{abstract}
Using pharmacologic and genetic approaches targeting actin or the actin-driving molecular motor, nonmuscle myosin II (NMII), we previously discovered an immediate, retrieval-independent, and long-lasting disruption of methamphetamine(METH-) and amphetamine-associated memories. A single intrabasolateral amygdala complex infusion or systemic administration of the NMII inhibitor Blebbistatin (Blebb) is sufficient to produce this disruption, which is selective, having no retrieval-independent effect on memories for fear, food reward, cocaine, or morphine. However, it was unclear if Blebb treatment would disrupt memories of other stimulants and amphetamine class drugs, such as nicotine (NIC) or mephedrone (MEPH; bath salts). Moreover, many individuals abuse multiple drugs, but it was unknown if Blebb could disrupt polydrug memories, or if the inclusion of another substance would render Blebb no longer able to disrupt METH-associated memories. Therefore, the present study had two primary goals: (1) to determine the ability of Blebb to disrupt NIC- or MEPHassociated memories, and (2) to determine the ability of METH to modify other unconditioned stimulus (US) associations' susceptibility to Blebb. To this end, using the conditional place preference model, mice were conditioned to NIC and MEPH alone or METH in combination with NIC, morphine, or foot shock. We report that, unlike METH, there was no retrievalindependent effect of Blebb on NIC- or MEPH-associated memories. However, similar to cocaine, reconsolidation of the memory for both drugs was disrupted. Further, when combined with METH administration, NIC- and morphine-, but not fear-, associated memories were rendered susceptible to disruption by Blebb. Given the high rate of polydrug use and the resurgence of METH use, these results have important implications for the treatment of substance use disorder.
\end{abstract}

The National Drug Threat Assessment (2017, NDTA) recently reported that in the United States, despite government imposed regulations on over-the-counter cold medication and decreases in methamphetamine (METH) laboratories, METH continues to be readily available to most of the USA. METH abuse has been steadily rising for the past $5 \mathrm{yr}$, complicated by a paradoxical drop in cost and increase in purity ( $>95 \%$ pure; NDTA, 2017). There are currently no FDA-approved pharmacotherapies for the treatment of any stimulant use disorder, including METH, and relapse rates remain high among those attempting abstinence.

In an effort to address the problem of high relapse, we recently discovered an actin-based strategy for targeting relapse-inducing METH-associated memories. Actin polymerization is the process of monomeric globular actin (G-actin) growing into complex, filamentous actin (F-actin) structures (Lin et al. 2005; Kramar et al. 2006), and is required for memory-promoting structural plasticity. F-actin rapidly stabilizes after fear-associated (Fischer et al. 2004; Mantzur et al. 2009; Rehberg et al. 2010; Rex et al. 2010b; Gavin et al. 2012), but not METH-associated learning (Young et al. 2014, 2015, 2016; Briggs et al. 2017), as indicated by differential susceptibility to actin depolymerizers, such as Latrunculin A. The sustained actin dynamics that result from METH-associated learning render these memories uniquely susceptible to disruption long after the learning event. In addition to METH-associated memory disruption by direct actin depolymerization in the basolateral amygdala complex (BLC), we have demonstrated similar results by indirectly targeting actin through the molecular motor, nonmuscle myosin II (NMII) (Young et al. 2016). Using genetic and

\section{Corresponding author: cmiller@scripps.edu}

Article is online at http://www.learnmem.org/cgi/doi/10.1101//m.046763.117. pharmacologic approaches, we previously demonstrated that NMII drives synaptic actin polymerization to support plasticity and learning in the hippocampus and BLC (Young et al. 2014, 2015,2016 , 2017; Briggs et al. 2017). Indeed, a single intra-BLC infusion or systemic administration of the NMII small molecule inhibitor (NMIIi) blebbistatin (Blebb) produces an immediate, retrieval-independent and long-lasting disruption of the storage of METH-associated memories (Young et al. 2014, 2015, 2016, 2017).

More recently, we found that amphetamine (AMP)-associated memories are similarly susceptible to Blebb, whereas cocaine(COC) and morphine- (MOR) associated memories are protected (Briggs et al. 2017). However, the mechanism through which METH- and AMP-, but not COC- or MOR-associated learning results in sustained actin dynamics and a persistent susceptibility of the resulting memory to NMIIi is unclear. Although, COC, $\mathrm{METH}$, and AMP are all stimulants, there are key differences in chemical structure, half-life, and mechanism of action that may contribute to memories associated with METH or AMP, but not COC, being susceptible to immediate, retrieval-independent disruption by NMIIi. METH is included in a group of drugs categorized as AMP-like drugs. Another in this category is mephedrone (MEPH), more commonly known as bath salts, and is a $\beta$-ketoamphetamine. Although a member of the AMP-like family, MEPH differs from METH and AMP in several ways, including half-

(C) 2018 Briggs et al. This article is distributed exclusively by Cold Spring Harbor Laboratory Press for the first 12 months after the full-issue publication date (see http://learnmem.cshlp.org/site/misc/terms.xhtml). After 12 months, it is available under a Creative Commons License (Attribution-NonCommercial 4.0 International), as described at http://creativecommons.org/licenses/by-nc/4.0/. 
life and trace amine-associated receptor 1 (TAAR1) binding affinity (Martinez-Clemente et al. 2013; Simmler et al. 2013, 2014). However, whether MEPH- or nicotine- (NIC; one of the most commonly used stimulates) associated memories are similarly susceptible to disruption by Blebb administration was unknown. Therefore, to gain mechanistic insights into NMII-susceptible memories as well as determine the breath of drug-associated memories vulnerable to disruption, we tested the effect of Blebb on MEPH- and NIC-associated memories.

Additionally, it was unclear if Blebb could affect polydrug memories, which are formed following the concurrent use of two or more drugs, or if the inclusion of an additional drug would render the memory no longer susceptible to Blebb-induced disruption. According to Treatment Episode Data Set (TEDS), polydrug use is more common that single drug use (Substance Abuse and Mental Health Services Administration and Quality 2004-2014). Polysubstance use develops for a variety of reasons, including the use of one drug to counteract or enhance the effects of another. For example, some individuals use an opioid to temper the effects of a stimulant, such as METH, to produce a greater high, or to achieve a unique set of desirable effects through the combination of substances (Ellinwood et al. 1976; Leri et al. 2003; Trujillo et al. 2011). Additionally, while overall rates are declining in the USA, smoking cigarettes remains prevalent among people with mental disorders, low social economic status, and people with a low level of education (SAMSHA). Moreover, approximately $71 \%$ of individuals that abuse illicit drugs also smoke cigarettes (Richter et al. 2002), and it is common for polysubstance users to have worse treatment outcomes (DeMaria et al. 2000; Downey et al. 2000).

Thus, we first examined whether Blebb could disrupt MEPHand NIC-associated memories. We next determined if Blebb could disrupt more complex memories. We previously found that Blebb disrupts METH-, but not MOR-, associated memories, but it was unclear if administration of both METH and MOR would render the combined memory susceptible to Blebb-induced disruption. We therefore tested whether Blebb could disrupt METH and MOR-associated memories, as well as METH and NIC-associated memories as they are also commonly abused together.

\section{Results}

\section{NMIli-mediated memory disruption does not extend to all drugs in the AMP class}

The effect of NMIIi on MEPH-associated memories was assessed. MEPH is both a member of the AMP class and a synthetic cathinone, the active stimulant in the khat plant (Catha edulis) (Meyer et al. 2010; Morris 2010; Carroll et al. 2012). To determine the optimal MEPH CPP dose with our protocol, two doses that have been previously published as sufficient to produce a place preference were tested (2.0 and $2.5 \mathrm{mg} / \mathrm{kg}$; IP; Fig. 1A; Karlsson et al. 2014). Mice received an IP injection of Blebb at $10 \mathrm{mg} / \mathrm{kg}, 15 \mathrm{~min}$ before a drug-free test. Twenty-four hours later, animals received a second preference test, but no additional Blebb or METH. We have previously shown that this protocol produces an immediate and lasting disruption of METH-associated memory and context-induced reinstatement of METH seeking that is not dependent on retrieval (Young et al. 2014, 2015, 2016, 2017; Briggs et al. 2017). A significant place preference was demonstrated following conditioning with the lower $2.0 \mathrm{mg} / \mathrm{kg}$ dose (Fig. 1B: Test $\times$ Compartment $F_{(2,40)}=18.74, P \leq 0.0001$; Compartment $F_{(1,20)}=22.35 P \leq$ 0.0001; Test: $\left.F_{(2,40)}=4.43, P \leq 0.01\right)$, but not the higher $2.5 \mathrm{mg} /$

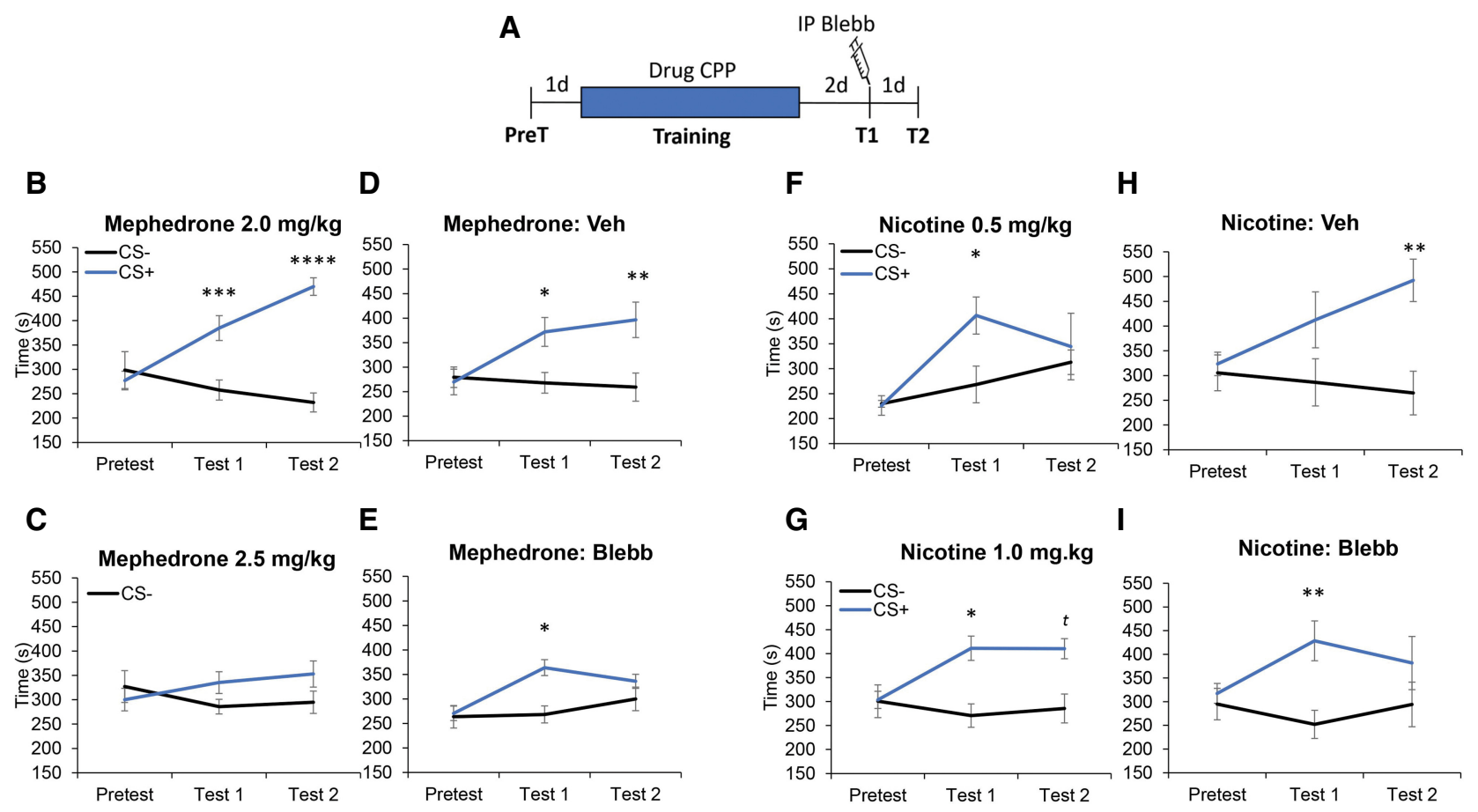

Figure 1. Nonmuscle myosin II inhibition disrupts reconsolidation of mephedrone- and nicotine-associated memories $(A)$ Schematic of the experimental design ((PreT) pretest, (T1) CPP test 1, (T2) CPP test 2). The establishment of MEPH CPP using two doses: (B) $2.0 \mathrm{mg} / \mathrm{kg}$ and (C) $2.5 \mathrm{mg} / \mathrm{kg}$. (D) Veh-treated mice demonstrated a significant MEPH CPP during Test 1 and 2. (E) Blebb-treated mice demonstrated a significant MEPH CPP during Test 1, but not during Test 2. The establishment of NIC CPP using two doses: $(F) 0.5 \mathrm{mg} / \mathrm{kg}$ and $(G) 1.0 \mathrm{mg} / \mathrm{kg}$. $(H)$ Veh-treated mice demonstrated a significant NIC CPP during Test 2. (I) Blebb-treated mice demonstrated a significant NIC CPP during Test 1 , but not during Test 2 . MEPH $2.0 \mathrm{mg} / \mathrm{kg} n=11 ; \mathrm{MEPH} 2.5 \mathrm{mg} / \mathrm{kg} n=12$; MEPH Veh $n=10$; MEPH Blebb $n=12$; NIC $0.5 \mathrm{mg} / \mathrm{kg} n=11$; NIC $1.0 \mathrm{mg} / \mathrm{kg} n=11$; NIC Veh $n=10$; NIC Blebb $n=10 .\left({ }^{*}\right) P<0.05,\left({ }^{* *}\right) P<0.01,\left({ }^{* \star *}\right) P<$ $0.001,\left({ }^{* * *}\right) P<0.0001$. Error bars represent \pm S.E.M. 
kg dose (Fig. 1C: Test $\times$ Compartment $F_{(2,44)}=2.53, P>0.05$; Compartment: $F_{(1,22)}=1.18, P>0.05$; Test: $\left.F_{(2,44)}=0.22, P>0.05\right)$. Next, a separate cohort of mice was conditioned with $2.0 \mathrm{mg} / \mathrm{kg}$ of $\mathrm{MEPH}$, before receiving an IP administration of vehicle (Veh) or Blebb 30 min prior to Test 1 (T1; Fig. 1A). As expected, Veh-treated mice displayed a significant preference for the CS+ compartment, the drug paired compartment, during Test 1 and 2 (Fig. 1D; Test $x$ Compartment $F_{(2,36)}=3.87, P>0.05$; Compartment: $F_{(1,18)}=8.24$, $P \leq 0.01$; Test $\left.F_{(2,36)}=2.52, P>0.05\right)$. Likewise, post-hoc analysis of the Blebb treatment group revealed that Blebb treatment did not have an immediate effect on MEPH-associated memory, as mice displayed a significant preference for the CS+ compartment (T1; Fig. 1E). However, Blebb treatment did disrupt reconsolidation, as evidenced by a lack of a place preference during Test 2 (T2; Fig. 1E; Test $\times$ Compartment $F_{(2,44)}=4.18, P>0.05$; Compartment: $F_{(1,22)}=5.65, P \leq 0.05 ;$ Test $\left.F_{(2,44)}=6.83, P \leq 0.01\right)$. This blockade of reconsolidation was consistent with our prior findings that systemic or intra-hippocampal injections of Blebb prior to test 1 disrupts the reconsolidation of COC-associated memories (Briggs et al. 2017). Indeed, a role for actin polymerization in the reconsolidation of other forms of memory has been reported (Mantzur et al. 2009; Rehberg et al. 2010; Ding et al. 2013; Li et al. 2015).

\section{NMIli disrupts reconsolidation of NIC-associated memories}

To examine the effect of NMIIi on NIC-associated memories, a sufficient dose of NIC to induce a CPP in mice was first determined using previously used doses (Ignatowska-Jankowska et al. 2013; Jackson et al. 2013). Mice were conditioned (Fig. 1A) to one of two NIC doses: 0.5 or $1.0 \mathrm{mg} / \mathrm{kg}$ (SC; Fig. 2A). Both doses resulted in a place preference during Test 1 , with a trend toward a preference during Test 2 using the $1.0 \mathrm{mg} / \mathrm{kg}$ dose $(0.5 \mathrm{mg} / \mathrm{kg}$, Fig. 1F: Test $\times$ Compartment: $F_{(2,40)}=2.98, \quad P>0.05$; Compartment: $F_{(1,20)}=$ 1.89, $P \leq 0.01$; Test: $F_{(2,40)}=8.12, P \leq 0.001 ; 1.0 \mathrm{mg} / \mathrm{kg}$, Fig. 1G: Test $\times$ Compartment: $F_{(2,36)}=4.71, P \leq 0.01$; Compartment: $F_{(1,18)}=$ 3.52, $P>0.05$; Test: $\left.F_{(2,36)}=2.03, P>0.05\right)$. Next, the effect of NMIIi was determined in NIC conditioned mice, using the 1.0 $\mathrm{mg} / \mathrm{kg}$ dose. Veh-treated mice demonstrated a significant CPP during Test 1 and 2 (Veh, Fig. $2 \mathrm{H}$ : Test $\times$ Compartment: $F_{(2,36)}=5.08$, $P \leq 0.01$; Compartment: $F_{(1,18)}=6.83, P \leq 0.01$; Test: $F_{(2,36)}=1.90$, $P>0.05)$. However, as with MEPH, Blebb injected $30 \mathrm{~min}$ prior to a drug-free preference test (Fig. $2 \mathrm{~A}$ ) resulted in a significant CPP during Test 1 , but not during Test 2 , which suggests a reconsolidation disruption (Veh, Fig. $1 \mathrm{H}$ : Test $\times$ Compartment: $F_{(2,36)}=5.08$, $P \leq 0.01$; Compartment: $F_{(1,18)}=6.83, P \leq 0.01$; Test: $F_{(2,36)}=1.90$, $P>0.05$; Blebb, Fig. 1I: Test $\times$ Compartment: $F_{(2,36)}=3.21, P \leq$ 0.05; Compartment: $F_{(1,18)}=4.68, P \leq 0.05$; Test: $F_{(2,36)}=0.77, P>$ $0.05)$. Together, these data indicate that NMIIi can disrupt reconsolidation of various types of drug-associated memories across drugs classes, but immediate disruption remains selective for METH and AMP-associated memories.

\section{METH confers NMIli susceptibility to NIC- and MOR-associated memories}

Next, we aimed to determine the effect of NMIIi on polydrug-associated memories, and determine the ability of METH to modify the susceptibility of other drug-associated memories that are resistant to NMIIi alone, including NIC (Fig. 1) and MOR, which we previously tested (Briggs et al. 2017). Mice were conditioned with METH and MOR or METH and NIC separately (drugs given on alternating days in the same context, Fig. 2A) followed by NMIIi $30 \mathrm{~min}$ prior to testing. Similar to our previous results when METH or AMP are delivered alone (Young et al. 2014, 2016, 2017; Briggs et al. 2017), but in contrast to when NIC is administered alone (Fig. 1),

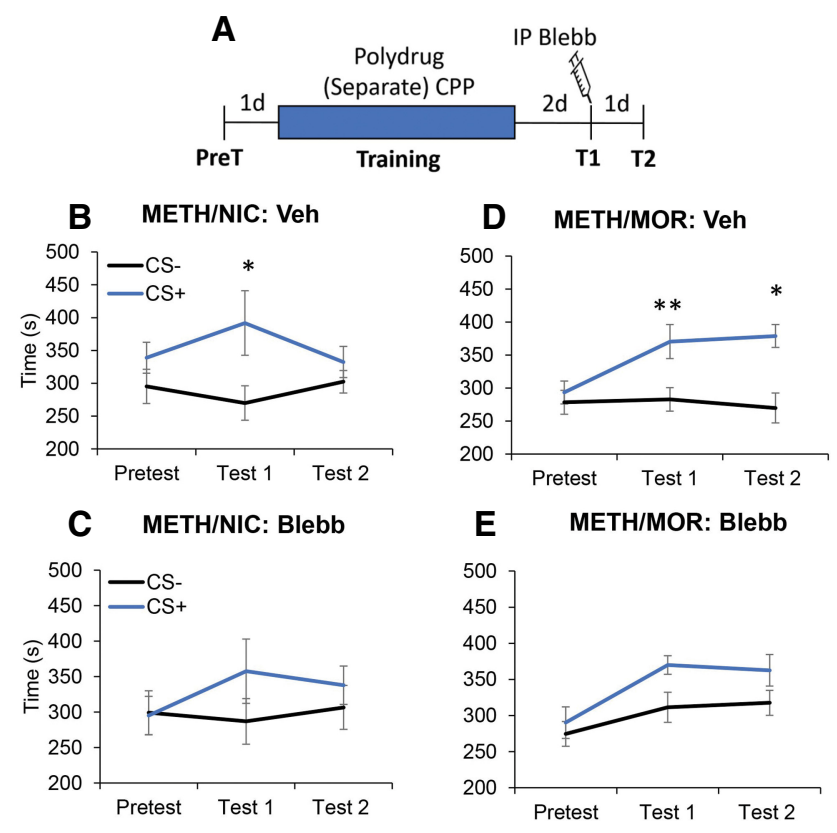

Figure 2. Nonmuscle myosin II inhibition disrupts polydrug-associated memories when the drugs are administered on alternating days (A) Schematic of the experimental design. (B) Veh-treated mice demonstrated a significant METH/NIC CPP during Test 1 , but not during Test 2. (C) Blebb-treated mice did not demonstrate a significant METH/NIC CPP during either test. $(D)$ Veh-treated mice demonstrated a significant METH/MOR CPP during Test 1 and 2. (E) Blebb-treated mice did not demonstrate a significant METH/MOR CPP during either test. METH/ NIC: Veh $n=10 ;$ METH/NIC: Blebb $n=10 ;$ METH/MOR: Veh $n=19$; METH/MOR: Blebb $n=19 ;\left(^{*}\right) P<0.05,\left({ }^{* *}\right) P<0.01$. Error bars represent \pm S.E.M.

Blebb-treated mice did not demonstrate a METH/NIC CPP during Test 1 or Test 2 (Fig. 3B) produced an immediate and long-lasting disruption of the combined memory for METH/NIC (Fig. 2B,C; Veh: Test $\times$ Compartment: $F_{(2,36)}=1.83, P>0.05$; Compartment: $F_{(1,18)}=5.71, P \leq 0.05$; Test: $F_{(2,36)}=0.18, P>0.05$; Blebb: Test $\times$ Compartment: $F_{(2,36)}=0.74, P>0.05$; Compartment: $F_{(1,18)}=$ $1.831 P>0.05$; Test: $\left.F_{(2,36)}=0.45, P>0.05\right)$. Post-hoc analysis revealed that Veh-treated animals did demonstrate a significant CPP during Test 1 , but not Test 2 . Veh-treated mice may have undergone extinction, which is why there was not a significant CPP during Test 2. Similarly, Blebb-treated mice did not demonstrate a significant METH/MOR CPP during Test 1 or Test 2 (Fig. 2D,E; Veh: Test $\times$ Compartment: $F_{(2,72)}=4.56, P \leq 0.01$; Compartment: $F_{(1,36)}=10.42, P \leq 0.01$; Test: $F_{(2,72)}=3.92, P \leq 0.05$; Blebb: Test $\times$ Compartment $F_{(2,72)}=0.73, P>0.05$; Compartment: $F_{(1,36)}=4.02$, $P \leq 0.05$; Test: $\left.F_{(2,72)}=6.85, P \leq 0.001\right)$. However, Veh-treated mice did demonstrate a significant CPP during both Test 1 and Test 2. Together, these results suggest that Blebb treatment can produce an immediate disruption of the combined memory for METH/NIC and METH/MOR.

Administering METH and NIC simultaneously (Fig. 3A) produced an aversion in Veh-treated mice (Fig. 3B; Test $x$ Compartment $F_{(2,44)}=1.48, P>0.05$; Compartment: $F_{(1,22)}=4.87$, $P \leq 0.05$; Test: $\left.F_{(2,44)}=0.16, P>0.05\right)$. Interestingly, the associated memory, which expressed as an avoidance of the CS+ compartment, was still reversed by Blebb treatment (Fig. 3C; Test $x$ Compartment: $F_{(2,44)}=0.10, P>0.05$; Compartment: $F_{(1,22)}=$ 4.74, $P \leq 0.05$; Test: $\left.F_{(2,44)}=0.01, P>0.05\right)$, suggesting a memory disruption of METH/NIC associations consistent with alternating administration (Fig. 2D,E). Similar to administration of METH/ 

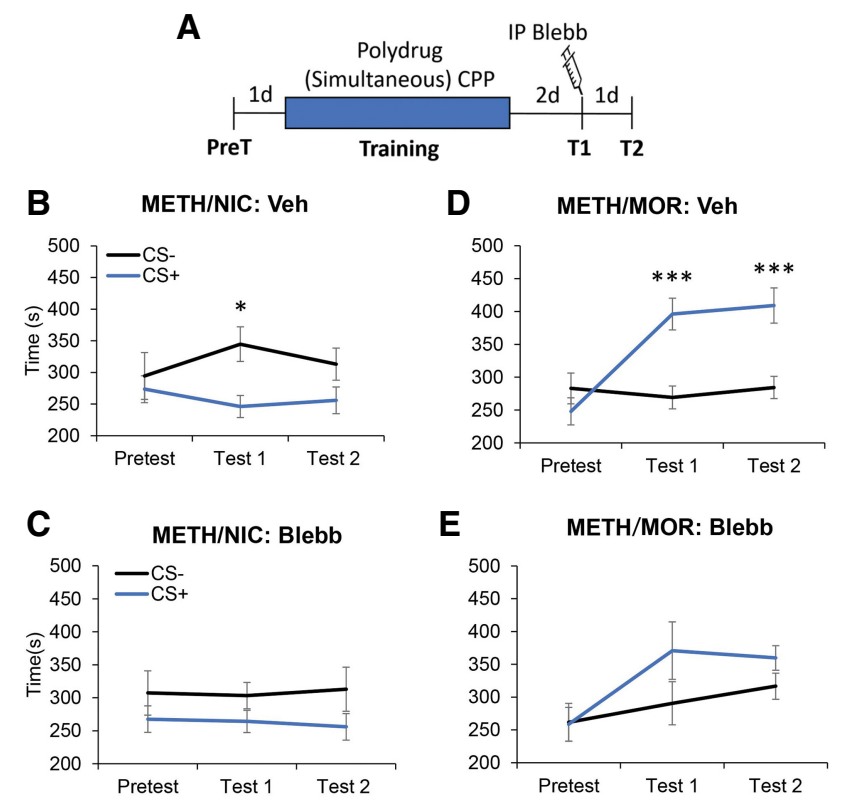

Figure 3. Nonmuscle myosin II inhibition disrupts polydrug-associated memories when the drugs are coadministered $(A)$ Schematic of the experimental design. $(B)$ Veh-treated mice demonstrated a significant aversion during Test 1, but not during Test 2, following METH/NIC CPP conditioning. (C) Blebb-treated mice did not demonstrate a significant METH/NIC CPP during either test. (D) Veh-treated mice demonstrated a significant METH/MOR CPP during Test 1 and 2. (E) Blebb-treated mice did not demonstrate a significant METH/MOR CPP during either test. METH/NIC; Veh $n=12 ; \mathrm{METH} / \mathrm{NIC}$; Blebb $n=12 ; \mathrm{METH} / \mathrm{MOR}$; Veh $n=12 ;$ METH/MOR; Blebb $n=11 ;\left(^{*}\right) P<0.05$, $\left({ }^{* * *}\right) P<0.001$. Error bars represent \pm S.E.M.

MOR on alternating days, simultaneous administration of METH/ MOR (i.e., "speedball") resulted in a strong CPP (Fig. 3D; Test $x$ Compartment: $F_{(2,44)}=15.89, P \leq 0.0001$; Compartment: $F_{(1,22)}=$ $8.81, P \leq 0.01$; Test: $\left.F_{(2,44)}=13.94, P \leq 0.0001\right)$ that was disrupted by Blebb (Fig. 3E; Test $\times$ Compartment: $F_{(2,40)}=1.33, P>0.05$; Compartment: $F_{(1,20)}=3.07, P>0.05$; Test: $\left.F_{(2,40)}=5.04, P \leq 0.01\right)$. In summary, these results suggest that NMIIi can disrupt METH-associated memories that are combined with MOR- and NIC-associated memories that were previously shown to be invulnerable at tested doses to NMIIi.

\section{METH fails to confer NMIli susceptibility to fear-associated memory}

Because NMIIi disrupts METH and AMP memories in a retrievalindependent manner by targeting them in storage, the issue of memory specificity is critical. As mentioned, we have previously demonstrated in publications and in the current results that NMIIi has no retrieval-independent effect on memories for COC, MOR, NIC, MEPH, food reward, or fear (Young et al. 2014, 2015, 2016, 2017; Briggs et al. 2017). However, the findings presented in Figures 3 and 4, in which coadministration of METH conferred susceptibility to NIC- and MOR-associated memories, indicate the importance of assessing the extent of METH's ability to modify memories for other USs. Therefore, we combined METH administration (US1) with foot shock (US2)-based cued fear conditioning, followed by pretest Blebb administration (Fig. 4A). Controls received saline (SAL) or METH prior to conditioning, and received Veh or Blebb prior to the memory retention test, resulting in four groups: SAL/Veh, SAL/Blebb, METH/Veh and METH/Blebb. The stimulant effects of METH prevented freezing during training
(Fig. 4B, Time $\times$ Treatment: $F_{(18,312)}=42.92, P \leq 0.0001$; Treatment: $F_{(3,52)}=28.06, \quad P \leq 0.0001$; Time: $\left.F_{(6,312)}=13.94, \quad P \leq 0.0001\right)$. Twenty-four hours later, memory was tested during the memory retention test (Fig. 4C). As we have previously reported (Young et al. 2014, 2016, 2017), SAL/Veh- and SAL/Blebb-treated animals displayed equivalent rates of freezing during a $24 \mathrm{~h}$ long-term memory test (Fig. 4C). The METH/Veh-treated mice displayed reduced freezing $(<50 \%$ of SAL-treated Veh or Blebb animals), whereas freezing in the METH/Blebb group was equivalent to SAL/VEHand SAL/Blebb-treated mice (Treatment: $F_{(3,19)}=5.82, P \leq 0.01$; post-hoc analysis, $P<0.05$ for $\mathrm{METH} / \mathrm{Veh}$ vs all others). These results reiterate that NMIIi is selective for METH-associated memories, and indicates that combining METH with a fear memory does not make the fear-associated memory susceptible to NMIIi disruption.

To confirm the consistency of the effect of a stimulant on fear conditioning (i.e., reduced freezing during training and testing), but also NMII's selective disruption of METH-associated memory rather than a general effect of combining a stimulant with fear conditioning, we repeated the experiment using COC (Fig. 4D). As with METH, COC-treated mice did not freeze during training due to the stimulant effects of the drug (Fig. $4 \mathrm{E}$; Time $\times$ Treatment: $F_{(18,114)}=4.43, \quad P \leq 0.0001$; Treatment: $F_{(3,19)}=6.20, \quad P \leq 0.001$; Time: $\left.F_{(6,114)}=11.48, P \leq 0.0001\right)$. As expected, SAL/Blebb-treated mice froze similarly as SAL/Veh-treated mice (Fig. 4F). However, unlike in the context of METH treatment, COC/Veh- and COC/ Blebb-treated mice froze significantly less than SAL/Veh- and SAL/Blebb-treated mice $\left(F_{(3,52)}=5.04, P \leq 0.01\right.$; post-hoc analysis, $P<0.05$ for METH/Veh and METH/Blebb vs SAL groups). These results agree with our previous findings that Blebb-treatment does not affect COC- or fear-associated memories.

\section{Discussion}

We have previously established that METH- and AMP-associated memories appear to be uniquely vulnerable to immediate and long-lasting disruption by NMIIi, as there is no effect on COC-, MOR-, fear- or food-associated memories (Young et al. 2014, 2015, 2016, 2017; Briggs et al. 2017). Here we extended these findings to show that NIC- and MEPH-associated contextual memories, at the doses tested here, were protected from immediate disruption by NMIIi. The MEPH findings indicate that not all memories associated with AMP-like drugs are susceptible to disruption by NMIIi. As with our previous findings with COC-associated memories, however, reconsolidation of NIC- $(1.0 \mathrm{mg} / \mathrm{kg})$ and MEPH- $(2.0$ $\mathrm{mg} / \mathrm{kg}$ ) associated contextual memories was blocked by NMIli. Additionally, we found that METH confers susceptibility to memories associated with two previously impervious drugs of abuse, NIC and MOR at $1.0 \mathrm{mg} / \mathrm{kg}$ and $2.0 \mathrm{mg} / \mathrm{kg}$, respectively, but not to an aversive fear-associated memory.

In addition to defining the therapeutic potential of a NMII inhibitor, studies determining the effect of NMIIi on memories associated with a range of commonly abused drugs have the potential to provide insight into the mechanism through which METH and AMP alter actin dynamics to produce their unusual susceptibility. MEPH (e.g., baths salts or cathinone) is a synthetic $\beta$-ketoamphetamine that has a similar chemical structure as AMP. In vitro studies of MEPH show its mechanism of action to be similar to AMP in its ability to bind to transporters for noradrenaline (NET), dopamine (DAT) and serotonin (SERT), and inhibit their reuptake (Dargan et al. 2011; Lopez-Arnau et al. 2012; Simmler et al. 2013, 2014; Green et al. 2014; Iversen et al. 2014; Luethi et al. 2017). Despite such overlap in the structure and mechanism of action, NMIIi did not result in the immediate disruption of MEPH-associated memory that we consistently observe with memories associated 
A

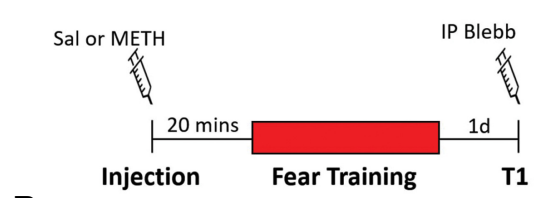

B

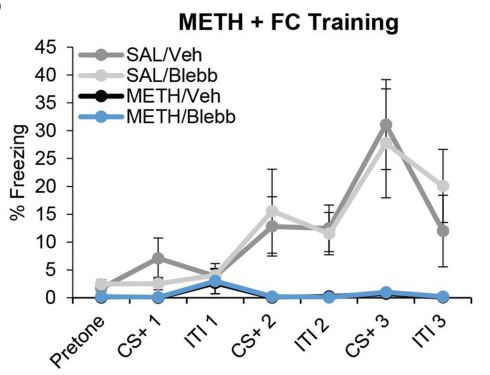

C

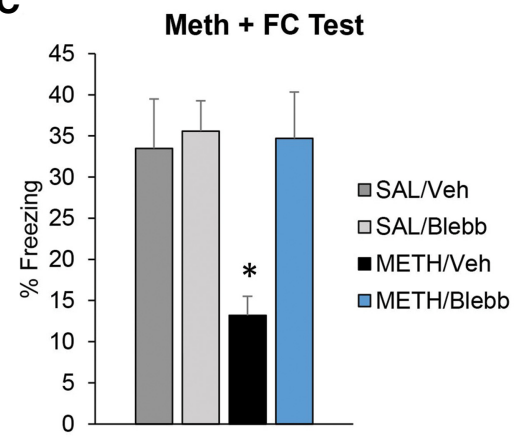

D

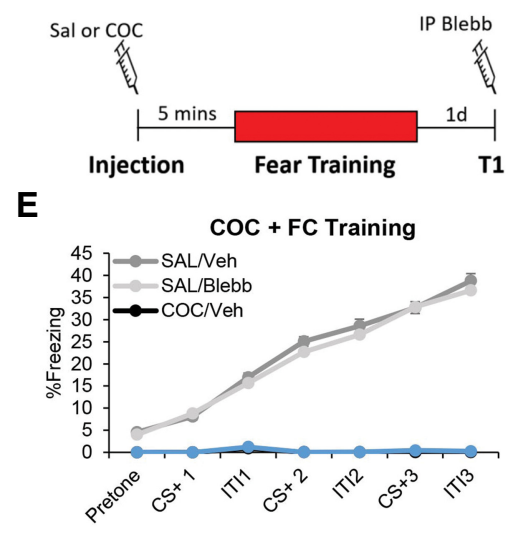

$\mathbf{F}$

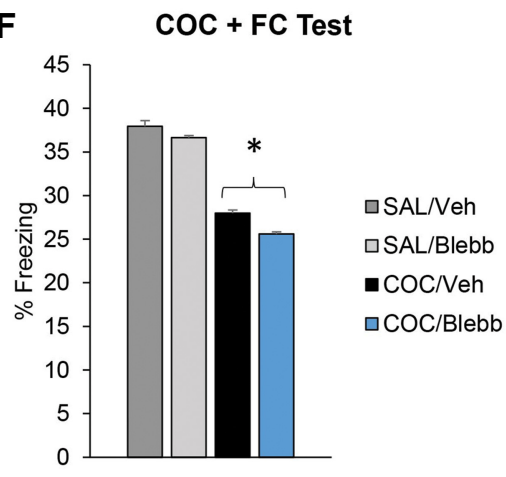

Figure 4. Nonmuscle myosin II inhibition fails to disrupt fear memory when training is paired with METH $(A)$ Schematic of the experimental design with METH administration at the time of fear conditioning. $(B)$ During training, SAL-treated mice demonstrated increased freezing throughout the session, whereas METH-treated mice did not. (C) SAL/Veh-, SAL/Blebb-, and METH/Blebb-treated mice demonstrated high rates of freezing during the retention test, but METH/Veh-treated mice had attenuated freezing. (D) Schematic of the experimental design with COC administration at the time of fear conditioning. (E) During training, SAL-treated mice demonstrated increased freezing throughout the session, whereas COC-treated mice did not. $(F)$ SAL/Veh- and SAL/Blebb-treated mice demonstrated high rates of freezing during the retention test, but $\mathrm{COC} / \mathrm{Blebb}$ - and $\mathrm{COC} /$ Veh-treated mice had similarly attenuated freezing. METH+FC: $\mathrm{SAL} /$ Veh $n=5$, SAL/Blebb $n=6$, METH/Veh $n=6$, METH/Blebb $n=6$; COC+FC: SAL/Veh $n=14$, SAL/Blebb $n=14$, COC/Veh $n=14$, COC/Blebb $n=14 .\left(^{*}\right) P<0.05$. Error bars represent \pm S.E.M.

with METH and AMP. This may be attributed to notable differences in the pharmacology between MEPH and METH/AMP.

Like COC, MEPH has a relatively short half-life of $2 \mathrm{~h}$ in humans and approximately 20-30 min in rodents. METH, on the other hand, has a half-life of $\sim 12 \mathrm{~h}$ in humans and $1 \mathrm{~h}$ in rodents (Cook et al. 1993; Harris et al. 2003; Martinez-Clemente et al. 2013). Furthermore, unlike METH, MEPH does not bind directly to TAAR1, which is a trace amine receptor that has been implicated in the internalization of monoamine transporters and enhancement of DA efflux (Zucchi et al. 2006; Xie and Miller 2009a,b), which leads to higher and more sustained levels of monoamines in the synaptic cleft (Di Chiara and Imperato 1988; Xie and Miller 2009b). TAAR1, however, may not underlie the selectivity of the memory, as METH-associated memories are not susceptible to inhibition of NMII within other brain structures of the neural circuit that also express TAAR1, such as the hippocampus and the nucleus accumbens (Briggs et al. 2017). An additional noteworthy difference between MEPH and METH/AMP is that they have different monoamine binding affinities. MEPH has a lower affinity for NET and DAT and a higher affinity for 5-HT2A and $\alpha 1 \mathrm{~A}$. Testing NMIIi on an AMP-like drug such as 3,4-methylenedioxy-metham- phetamine (MDMA; ecstasy) may help to address these questions. MDMA is similar to METH/AMP in terms of half-life $(\sim 1 \mathrm{~h}$ in rodents) and TAAR1 binding affinity, but is more similar to MEPH in its NET affinity and, of the four AMP-related drugs, has the highest binding affinity for SERT (Baumann et al. 2009; Simmler et al. 2013). Unfortunately, in testing MDMA for the current study, place preference was inconsistent in controls between cohorts. This is, perhaps, not surprising, as MDMA can lead to impaired emotional memory (Doss et al. 2018).

Additionally, determining the role of NMIIi on polydrug memories allows for further examination of memory allocation. We hypothesized that METH-associated learning at (Fig. 3) or near the time (Fig. 2) of NIC- or MOR-associated learning would alter the actin stability underlying NIC- and MOR-associated memories, rendering these associations newly susceptible to Blebb. However, two other possibilities were equally possible: (1) That the METH-associated memory would be disrupted, but the NIC- or MOR-associated memory would be sustained. This result would have manifested as a clear preference for the CS+. (2) That the formation of the additional NIC- or MOR-associated memory would alter the METH-associated memory in such a way that it was no longer susceptible to NMIIi. This result would have also presented as a clear preference for the CS+. The discovery that the contextual place preference memory was lost immediately following systemic Blebb treatment (Figs. $2,3)$ is consistent with our hypothesis that METH conferred susceptibility to memories for NIC and MOR. Together with current memory allocation data and our previous data revealing the actin depolymerization via latruculin $\mathrm{A}$ and NMIIi eliminates dendritic spines (Young et al. 2014, 2015, 2016) resulting in altered METH-associated memory in the BLA, but not the CA1, our current data suggests that the METH- plus NIC- or MOR-associated memories may have been allocated to the same neurons and, perhaps, even dendritic spines, where actin remained dynamic long after learning, rendering the memories susceptible to disruption by NMIIi. However, measuring dendritic spine density in mice that have undergone our polydrug behavioral paradigm needs to be done.

In testing polydrug use over time (Fig. 2), each delivery of METH and NIC or MOR was separated by $24 \mathrm{~h}$, but paired with the same context. It may be that on each training day in which NIC or MOR were administered, the US inputs associated with these drugs were preferentially allocated to BLC neurons and/or spines with actively cycling actin or another mechanism (e.g., increased CREB) as a result of separate METH pairings in the same $\mathrm{CS}+$ context. Alternatively, NIC or MOR pairings may have reactivated the METH-associated memory trace in the BLC each time, also leading to allocation of the NIC/MOR trace to METH-associated neurons/spines and an updating of the trace with new information to incorporate NIC/MOR associations. Consistent with 
the notion of prior neuronal activity driving memory allocation, increasing neuronal activity through manipulations of CREB or voltage-gated $\mathrm{K}+$ channels in the BLC can regulate which neurons a memory is allocated to in the engram (Han et al. 2009; Zhou et al. 2009; Yiu et al. 2014). Further studies, including self-administration reinstatement experiments, will need to be performed to determine if the order of drug delivery (i.e., METH first or second) influences the susceptibility of NIC/MOR memories. We predict similar results if METH is given on the second training day, as METH would then precede NIC/MOR treatment on the subsequent days and training would "end" with METH, which should leave the actin cytoskeleton dynamic and susceptible to NMIIi.

In the case of simultaneous drug administration (Fig. 3), it is also possible, in addition to the memory allocation process described above, that the combined drug-associated memories of METH/MOR and METH/NIC could result in a distinct memory supported by perpetually cycling actin when compared to a METH-, MOR-, or NIC-associated memory alone. Indeed, the combination of a stimulant and an opioid ("speedball") has been shown to be synergistic on both a behavioral and molecular level. That is, the effect of the combination is significantly greater than the sum of both drugs and distinct from each drug alone (Mori et al. 2004; Ito et al. 2007; Trujillo et al. 2011; Pattison et al. 2014). This could result in single US in terms of the mice's perception and neuronal link to the CS+ context. Additionally, we showed that the simultaneously administration of METH and NIC produced an aversion in Veh-treated mice. This effect is unlikely to be due to direct effects of coadministration on the amygdala, but rather, structures that mediate drug aversion, such as the medial and lateral habenula (Matsumoto and Hikosaka 2007; Fowler et al. 2011; Frahm et al. 2011; Fowler and Kenny 2012; Maroteaux and Mameli 2012; Jhou et al. 2013; Velasquez et al. 2014; Zapata et al. 2017).

To further address the possibility that learning a METH-cue association at the same time as another form of learning creates a unique, combined memory, we determined the impact of METH on fear-associated learning. We previously established that NMIIi prior to testing has no effect on fear memory (Young et al. 2014, 2016, 2017). Following training to a tone (CS1) with METH or COC (US1) and foot shock (US2), the two memories (US1-CS1 and US2-CS1) appeared to compete for expression, as evidenced by reduced freezing in the METH/Veh-treated mice (Fig. 4C). The reduced freezing displayed by $\mathrm{METH} / \mathrm{Veh}$-treated mice is interpreted as being the result of opposing conditioned responses (CRs) to the CS tone due to training with two USs, specifically, locomotion connected to US1 (METH) and freezing connected to US2 (foot shock). The restoration of freezing to SAL-treated mice rates in the METH/Blebb-treated group is consistent with the interpretation that Blebb selectively excised the METH-associated memory, leaving the fear-associated memory intact (remaining $\mathrm{CR}=$ freezing). This is contrary to the effect of combining METH with NIC or MOR, which conferred susceptibility to the NIC and MOR associations (no remaining $\mathrm{CR}=$ no place preference). This is consistent with opposing conditioned responses (CRs) to US1, a rewarding, locomotor-inducing stimulant (METH or COC), versus US2, an aversive stimulus that elicits freezing. Importantly, pretest administration of Blebb to animals that received METH during training resulted in a return of freezing to Sal-treated mice rates, suggesting a loss of the US1 (METH)-CS1 associated memory, but maintenance of the US2 (foot shock)-CS1 associated memory. In contrast, freezing remained reduced in COC/Blebb-treated mice, suggesting no effect of NMIIi on the CS association with either US1 (COC) or US2 (foot shock). This is consistent with our prior findings of METH-, but not COC-, associated memories being susceptible to NMIIi, and suggests that simultaneous association of two USs with one CS does not result in a single, inseparable memory trace.

In addition, the conference of NMIIi susceptibility to NIC- or MOR-associated memories, but not a fear-associated memory, by METH may be related to the differential valence of the USs. It is well established that the BLC is an emotional memory center that processes, integrates and responds to stimuli bearing both negative and positive valence ( $\mathrm{O}^{\prime}$ Neill et al. 2018). Indeed, fairly distinct populations of positive and negative valence-responsive neurons have been identified in rodents and primates (Paton et al. 2006; Shabel and Janak 2009; Xiu et al. 2014; Beyeler et al. 2016). Importantly, this includes neurons that differentially respond to positive (NIC) and negative (foot shock) USs (Gore et al. 2015). Further, Kim et al., recently demonstrated cell populations exist in the BLC for stimuli of positive and negative valence that can be distinguished by their molecular makeup and anatomical location within the BLC (Kim et al. 2017). Thus, we are intrigued by the possibility that memories associated with METH and other drugs of abuse are allocated to the same positive valence neurons, rendering previously resistant memories susceptible to NMIIi. In contrast, the lack of an effect of Blebb on fear-associated memory in the context of METH suggests a separation of the METH and foot shock-related engrams to unique, positive and negative valence neurons. Future studies will delve into the circuitry and cell-specific molecular signatures of these various combined associations in order to better understand the mechanisms of memory allocation, as well as studies designed to determine the temporal constraints and susceptibility of other appetitive, but nondrug, memories.

In summary, these results reveal that drug-associated memories once thought to be protected from NMIIi-mediated alterations may be vulnerable if METH-associated learning also occurs. This has important implications, as it suggests a significant increase in the potential population that could benefit from an NMII-based therapeutic and points to the importance of determining the full extent of polydrug susceptibility. Indeed, we are currently working to develop a clinically safe NMII inhibitor for the reduction of relapse risk.

\section{Material and Methods}

\section{Animals}

Adult, 8-10 wk old male C57BL/6 mice (25-30 g, Jackson Laboratory) were housed under a 12:12 light-dark cycle, with food and water ad libitum. All procedures were performed in accordance with the Scripps Research Institutional Animal Care and Use Committee. Mice were handled for 3-5 d before behavioral testing. Sample size for all experiments was based on prior experience and standards in the field. Randomization was performed such that all behaviors were equally balanced between groups before Veh or Blebb treatment.

\section{Drugs}

Methamphetamine hydrochloride (METH, $2.0 \mathrm{mg} / \mathrm{kg}$, i.p., SigmaAldrich), mephedrone hydrochloride (racemic mixture; MEPH, 2.0 and $2.5 \mathrm{mg} / \mathrm{kg}$, i.p., Sigma-Aldrich), Nicotine Bitartrate Dihydrate (NIC, 0.5 and $1.0 \mathrm{mg} / \mathrm{kg}$, s.c, Sigma-Aldrich), and Morphine hydrochloride (MOR, $10 \mathrm{mg} / \mathrm{kg}$, i.p., Sigma-Aldrich) were dissolved in sterile $0.9 \%$ and administered at the denoted doses. Racemic (+/-) Blebb (Tocris) was diluted to $1 \mathrm{mg} / \mathrm{mL}$ in a vehicle of $0.9 \%$ SAL and $6.7 \%$ DMSO/25\% Hydroxypropyl $\beta$-Cyclodextrin $(\mathrm{HP} \beta \mathrm{CD})$ and administered at a dose of $10 \mathrm{mg} / \mathrm{kg}$ (i.p.) (Young et al. 2016; Briggs et al. 2017; Young et al. 2017). 


\section{Condition place preference}

CPP was performed using methods and equipment previously described (Miller and Marshall 2004; Young et al. 2014) with a few modifications. Briefly, pretesting took place over $2 \mathrm{~d}$, during which mice were allowed to freely explore the CPP apparatus for $30 \mathrm{~min}$ each day. The final $15 \mathrm{~min}$ of the second pretest session were used for analysis of pretest preference. As mice did not show a significant preference for one chamber over the other, a nonbiased procedure was used, and mice were counterbalanced for which chamber they received drug or SAL. Mice were trained over four consecutive days with twice daily training sessions, such that mice received both drug and SAL each day (Figs. 2A, 3A). Mice received SAL during the first training session (a.m. session) and drug during the second training session (p.m. session), which were separated by $4 \mathrm{~h}$ to minimize the potential for residual drug from one session influencing another session (Figs. 1A, 2A). For polydrug (separate) experiments, drug was administered on alternative training days, during the p.m. session. Mice were conditioned for $6 \mathrm{~d}$, which resulted in three pairings of each drug to the same context, and six pairings of SAL to the alternative context (Figs. 1A, 4A). Testing consisted of $15 \mathrm{~min}$ free access to the CPP apparatus and was conducted $2 \mathrm{~d}$ after the final day of training. Blebb (IP) was given once, $30 \mathrm{~min}$ prior to Test 1.

\section{Drug fear conditioning}

This task was performed as previously described (Rex et al. 2010a; Sillivan et al. 2017) with few modifications (Fig. 4A). Auditory fear conditioning was conducted in three stages, habituation, training and testing. During habituation, mice were allowed to explore context $\mathrm{A}$ in three, 4-min sessions, for a total of $12 \mathrm{~min}$ of habituation. Context A consisted of grid floors to deliver shock, a dim corner light in the room, no overhead lights, and 70\% ethanol used for cleaning. Training took place $24 \mathrm{~h}$ later. Twenty or 10 min prior to being placed back in to context $\mathrm{A}$, mice received an injection of METH or COC, respectively. Training consisted of 2 min of exploration followed by three, 30 sec CS US pairings that coterminated with a $0.5 \mathrm{~mA}$ footshock (US) separated by a 120 sec intertone interval (ITI). The CS was an $85 \mathrm{~dB}, 10 \mathrm{kHz}$ tone. Training ended $1 \mathrm{~min}$ after the final shock. Memory retention tests were performed in a novel, context B, $24 \mathrm{~h}$ following training. Context B consisted of smooth plastic flooring, a plastic insert on the walls of the chamber, bright overhead room lights, orange extract under the flooring, a $65 \mathrm{~dB}$ white noise and isopropanol used for cleaning. Following a 3-min exploration in Context B, mice were given a 3 min tone presentation in the absence of the US (tone only). Immobility (freezing) was tracked with a camera inside the chamber and analyzed with Ethovision software (Version 11.5, Noldus). To account for refractory contextual freezing in the measurement of auditory fear memories, pretone freezing was subtracted from CS freezing for extinction and recall sessions.

\section{Statistical analysis}

Two-way repeated measures ANOVAs (Test x Compartment) were used to asses CPP preference across tests and FC training data over time. Bonferroni post-hoc tests were used when appropriate, as done previously (Briggs et al. 2017). One-way ANOVA (Treatment) was used to analyze FC data. Statistical significance was set at $P \leq 0.05$ and variation is presented as standard error of the mean. Twenty-one mice were excluded from analysis because they had an initial bias, which was defined as a $300+$ second difference between the black and the white compartment during the pretest. One mouse was excluded due to experimenter error.

\section{Acknowledgments}

The authors thank the Scripps Florida Behavior Core for providing behavioral equipment. This work was supported by grants from the National Institutes of Health to C.A.M. (R01DA034116, UH2/ 3NS096833, and R01DA034116-03S1 Diversity Supplement to support S.B.B.).

\section{References}

Baumann MH, Zolkowska D, Kim I, Scheidweiler KB, Rothman RB, Huestis MA. 2009. Effects of dose and route of administration on pharmacokinetics of (+ or -)-3,4-methylenedioxymethamphetamine in the rat. Drug Metab Dispos 37: 2163-2170.

Beyeler A, Namburi P, Glober GF, Simonnet C, Calhoon GG, Conyers GF, Luck R, Wildes CP, Tye KM. 2016. Divergent routing of positive and negative information from the amygdala during memory retrieval. Neuron 90: 348-361.

Briggs SB, Blouin AM, Young EJ, Rumbaugh G, Miller CA. 2017. Memory disrupting effects of nonmuscle myosin II inhibition depend on the class of abused drug and brain region. Learn Mem 24: 70-75.

Carroll FI, Lewin AH, Mascarella SW, Seltzman HH, Reddy PA. 2012. Designer drugs: a medicinal chemistry perspective. Ann N Y Acad Sci 1248: $18-38$.

Cook CE, Jeffcoat AR, Hill JM, Pugh DE, Patetta PK, Sadler BM, White WR, Perez-Reyes M. 1993. Pharmacokinetics of methamphetamine selfadministered to human subjects by smoking S-(+)-methamphetamine hydrochloride. Drug Metab Dispos 21: 717-723.

Dargan PI, Sedefov R, Gallegos A, Wood DM. 2011. The pharmacology and toxicology of the synthetic cathinone mephedrone (4methylmethcathinone). Drug Test Anal 3: 454-463.

DeMaria PAJr, Sterling R, Weinstein SP. 2000. The effect of stimulant and sedative use on treatment outcome of patients admitted to methadone maintenance treatment. Am J Addict 9: 145-153.

Di Chiara G, Imperato A. 1988. Drugs abused by humans preferentially increase synaptic dopamine concentrations in the mesolimbic system of freely moving rats. Proc Natl Acad Sci 85: 5274-5278.

Ding ZB, Wu P, Luo YX, Shi HS, Shen HW, Wang SJ, Lu L. 2013. Region-specific role of Rac in nucleus accumbens core and basolateral amygdala in consolidation and reconsolidation of cocaine-associated cue memory in rats. Psychopharmacology (Berl) 228: 427-437.

Doss MK, Weafer J, Gallo DA, de Wit H. 2018. MDMA impairs both the encoding and retrieval of emotional recollections. Neuropsychopharmacol 43: 791-800.

Downey KK, Helmus TC, Schuster CR. 2000. Treatment of heroindependent poly-drug abusers with contingency management and buprenorphine maintenance. Exp Clin Psychopharmacol 8: 176-184.

Ellinwood EHJr, Eibergen RD, Kilbey MM. 1976. Stimulants: interaction with clinically relevant drugs. Ann N Y Acad Sci 281: 393-408.

Fischer A, Sananbenesi F, Schrick C, Spiess J, Radulovic J. 2004. Distinct roles of hippocampal de novo protein synthesis and actin rearrangement in extinction of contextual fear. J Neurosci 24: 1962-1966.

Fowler CD, Kenny PJ. 2012. Habenular signaling in nicotine reinforcement. Neuropsychopharmacol 37: 306-307.

Fowler CD, Lu Q, Johnson PM, Marks MJ, Kenny PJ. 2011. Habenular alpha 5 nicotinic receptor subunit signalling controls nicotine intake. Nature 471: $597-601$.

Frahm S, Slimak MA, Ferrarese L, Santos-Torres J, Antolin-Fontes B, Auer S, Filkin S, Pons S, Fontaine JF, Tsetlin V, et al. 2011. Aversion to nicotine is regulated by the balanced activity of beta 4 and alpha 5 nicotinic receptor subunits in the medial habenula. Neuron 70: 522-535.

Gavin CF, Rubio MD, Young E, Miller C, Rumbaugh G. 2012. Myosin II motor activity in the lateral amygdala is required for fear memory consolidation. Learn Mem 19: 9-14.

Gore F, Schwartz EC, Brangers BC, Aladi S, Stujenske JM, Likhtik E, Russo MJ, Gordon JA, Salzman CD, Axel R. 2015. Neural representations of unconditioned stimuli in basolateral amygdala mediate innate and learned responses. Cell 162: 134-145.

Green AR, King MV, Shortall SE, Fone KC. 2014. The preclinical pharmacology of mephedrone; not just MDMA by another name. $\mathrm{Br} J$ Pharmacol 171: 2251-2268.

Han JH, Kushner SA, Yiu AP, Hsiang HL, Buch T, Waisman A, Bontempi B, Neve RL, Frankland PW, Josselyn SA. 2009. Selective erasure of a fear memory. Science 323: 1492-1496.

Harris DS, Boxenbaum H, Everhart ET, Sequeira G, Mendelson JE, Jones RT. 2003. The bioavailability of intranasal and smoked methamphetamine. Clin Pharmacol Ther 74: 475-486.

Ignatowska-Jankowska BM, Muldoon PP, Lichtman AH, Damaj MI. 2013. The cannabinoid CB2 receptor is necessary for nicotine-conditioned place preference, but not other behavioral effects of nicotine in mice. Psychopharmacology (Berl) 229: 591-601. 
Ito S, Mori T, Namiki M, Suzuki T, Sawaguchi T. 2007. Complicated interaction between psychostimulants and morphine in expression of phenotype of behavior in the dopaminergic system of BALB/c mice. J Pharmacol Sci 105: 326-333.

Iversen L, White M, Treble R. 2014. Designer psychostimulants: pharmacology and differences. Neuropharmacology 87: 59-65.

Jackson KJ, McLaughlin JP, Carroll FI, Damaj MI. 2013. Effects of the kappa opioid receptor antagonist, norbinaltorphimine, on stress and drug-induced reinstatement of nicotine-conditioned place preference in mice. Psychopharmacology (Berl) 226: 763-768.

Jhou TC, Good CH, Rowley CS, Xu SP, Wang HK, Burnham NW, Hoffman AF, Lupica CR, Ikemoto S. 2013. Cocaine drives aversive conditioning via delayed activation of dopamine-responsive habenular and midbrain pathways. I Neurosci 33: 7501-7512.

Karlsson L, Andersson M, Kronstrand R, Kugelberg FC. 2014. Mephedrone, methylone and 3,4-methylenedioxypyrovalerone (MDPV) induce conditioned place preference in mice. Basic Clin Pharmacol Toxicol 115: 411-416.

Kim J, Zhang XY, Muralidhar S, LeBlanc SA, Tonegawa S. 2017. Basolateral to central amygdala neural circuits for appetitive behaviors. Neuron 1464-1479 e5.

Kramar EA, Lin B, Rex CS, Gall CM, Lynch G. 2006. Integrin-driven actin polymerization consolidates long-term potentiation. Proc Natl Acad Sci 103: $5579-5584$.

Leri F, Bruneau J, Stewart J. 2003. Understanding polydrug use: review of heroin and cocaine co-use. Addiction 98: 7-22.

Li G, Wang Y, Yan M, Xu Y, Song X, Li Q, Zhang J, Ma H, Wu Y. 2015. Inhibition of actin polymerization in the NAc shell inhibits morphine-induced CPP by disrupting its reconsolidation. Sci Rep 5: 16283.

Lin B, Kramar EA, Bi XN, Brucher FA, Gall CM, Lynch G. 2005. Theta stimulation polymerizes actin in dendritic spines of hippocampus. J Neurosci 25: 2062-2069.

Lopez-Arnau R, Martinez-Clemente J, Pubill D, Escubedo E, Camarasa J. 2012. Comparative neuropharmacology of three psychostimulant cathinone derivatives: butylone, mephedrone and methylone. $\mathrm{Br} \mathrm{J}$ Pharmacol 167: 407-420.

Luethi D, Kolaczynska KE, Docci L, Krahenbuhl S, Hoener MC, Liechti ME. 2017. Pharmacological profile of mephedrone analogs and related new psychoactive substances. Neuropharmacology 134: 4-12.

Mantzur L, Joels G, Lamprecht R. 2009. Actin polymerization in lateral amygdala is essential for fear memory formation. Neurobiol Learn Mem 91: $85-88$.

Maroteaux M, Mameli M. 2012. Cocaine evokes projection-specific synaptic plasticity of lateral habenula neurons. J Neurosci 32: 12641-12646.

Martinez-Clemente J, Lopez-Arnau R, Carbo M, Pubill D, Camarasa J, Escubedo E. 2013. Mephedrone pharmacokinetics after intravenous and oral administration in rats: relation to pharmacodynamics. Psychopharmacology (Berl) 229: 295-306.

Matsumoto M, Hikosaka O. 2007. Lateral habenula as a source of negative reward signals in dopamine neurons. Nature 447: 1111-1115.

Meyer MR, Wilhelm J, Peters FT, Maurer HH. 2010. Beta-keto amphetamines: studies on the metabolism of the designer drug mephedrone and toxicological detection of mephedrone, butylone, and methylone in urine using gas chromatography-mass spectrometry. Anal Bioanal Chem 397: 1225-1233.

Miller CA, Marshall JF. 2004. Altered prelimbic cortex output during cue-elicited drug seeking. J Neurosci 24: 6889-6897.

Mori T, Ito S, Narita M, Suzuki T, Sawaguchi T. 2004. Combined effects of psychostimulants and morphine on locomotor activity in mice. J Pharmacol Sci 96: 450-458.

Morris K. 2010. UK places generic ban on mephedrone drug family. Lancet 375: $1333-1334$.

O'Neill P, Gore F, Salzman D. 2018. Basolateral amygdala circuitry in positive and negative valence. Curr Opin Neurobiol 49: 175-183.

Paton JJ, Belova MA, Morrison SE, Salzman CD. 2006. The primate amygdala represents the positive and negative value of visual stimuli during learning. Nature 439: 865-870.

Pattison LP, McIntosh S, Sexton T, Childers SR, Hemby SE. 2014. Changes in dopamine transporter binding in nucleus accumbens following chronic self-administration cocaine: heroin combinations. Synapse 68: 437-444.

Rehberg K, Bergado-Acosta JR, Koch JC, Stork O. 2010. Disruption of fear memory consolidation and reconsolidation by actin filament arrest in the basolateral amygdala. Neurobiol Learn Mem 94: 117-126.
Rex CS, Gavin CF, Rubio MD, Kramar EA, Chen LY, Jia Y, Huganir RL, Muzyczka N, Gall CM, Miller CA, et al. 2010a. Myosin IIb regulates actin dynamics during synaptic plasticity and memory formation. Neuron 67: 603-617.

Rex CS, Gavin CF, Rubio MD, Kramar EA, Chen LY, Jia Y, Huganir RL, Muzyczka N, Gall CM, Miller CA, et al. 2010b. Myosin IIb regulates actin dynamics during synaptic plasticity and memory formation. Neuron 67: 603-617.

Richter KP, Ahluwalia HK, Mosier MC, Nazir N, Ahluwalia JS. 2002. A population-based study of cigarette smoking among illicit drug users in the United States. Addiction 97: 861-869.

Shabel SJ, Janak PH. 2009. Substantial similarity in amygdala neuronal activity during conditioned appetitive and aversive emotional arousal. Proc Natl Acad Sci 106: 15031-15036.

Sillivan SE, Joseph NF, Jamieson S, King ML, Chevere-Torres I, Fuentes I, Shumyatsky GP, Brantley AF, Rumbaugh G, Miller CA. 2017. Susceptibility and resilience to posttraumatic stress disorder-like behaviors in inbred mice. Biol Psychiatry 82: 924-933.

Simmler LD, Buser TA, Donzelli M, Schramm Y, Dieu LH, Huwyler J, Chaboz S, Hoener MC, Liechti ME. 2013. Pharmacological characterization of designer cathinones in vitro. Br J Pharmacol 168: $458-470$.

Simmler LD, Rickli A, Hoener MC, Liechti ME. 2014. Monoamine transporter and receptor interaction profiles of a new series of designer cathinones. Neuropharmacology 79: 152-160.

Substance Abuse and Mental Health Services Administration, Center for Behavioral Health Statistics and Quality. Treatment Episode Data Set (TEDS): 2004-2014. National Admissions to Substance Abuse Treatment Services. BHSIS Series S-84, HHS Publication No. (SMA) 16-4986. Rockville, MD: Substance Abuse and Mental Heath Services Administration, 2016. https://www.samhsa.gov/data/sites/default/files/ 2014_Treatment_Episode_Data_Set_National_Admissions_9_19_16.pdf.

Trujillo KA, Smith ML, Guaderrama MM. 2011. Powerful behavioral interactions between methamphetamine and morphine. Pharmacol Biochem Behav 99: 451-458.

Velasquez KM, Molfese DL, Salas R. 2014. The role of the habenula in drug addiction. Front Hum Neurosci 8: 174.

Xie Z, Miller GM. 2009a. A receptor mechanism for methamphetamine action in dopamine transporter regulation in brain. J Pharmacol Exp Ther 330: $316-325$

Xie Z, Miller GM. 2009b. Trace amine-associated receptor 1 as a monoaminergic modulator in brain. Biochem Pharmacol 78: 1095-1104.

Xiu JB, Zhang Q, Zhou T, Zhou TT, Chen Y, Hu HL. 2014. Visualizing an emotional valence map in the limbic forebrain by TAI-FISH. Nat Neurosci 17: 1552-1559.

Yiu AP, Mercaldo V, Yan C, Richards B, Rashid AJ, Hsiang HLL, Pressey J, Mahadevan V, Tran MM, Kushner SA, et al. 2014. Neurons are recruited to a memory trace based on relative neuronal excitability immediately before training. Neuron 83: 722-735.

Young EJ, Aceti M, Griggs EM, Fuchs RA, Zigmond Z, Rumbaugh G, Miller CA. 2014. Selective, retrieval-independent disruption of methamphetamine-associated memory by actin depolymerization. Biol Psychiatry 75: 96-104.

Young EJ, Briggs SB, Miller CA. 2015. The actin cytoskeleton as a therapeutic target for the prevention of relapse to methamphetamine use. CNS Neurol Disord Drug Targets 14: 731-737.

Young EJ, Blouin AM, Briggs SB, Sillivan SE, Lin L, Cameron MD, Rumbaugh G, Miller CA. 2016. Nonmuscle myosin IIB as a therapeutic target for the prevention of relapse to methamphetamine use. Mol Psychiatry 21: 615-623.

Young EJ, Briggs SB, Rumbaugh G, Miller CA. 2017. Nonmuscle myosin II inhibition disrupts methamphetamine-associated memory in females and adolescents. Neurobiol Learn Mem 139: 109-116.

Zapata A, Hwang EK, Lupica CR. 2017. Lateral habenula involvement in impulsive cocaine seeking. Neuropsychopharmacol 42: 1103-1112.

Zhou Y, Won J, Karlsson MG, Zhou M, Rogerson T, Balaji J, Neve R, Poirazi P, Silva AJ. 2009. CREB regulates excitability and the allocation of memory to subsets of neurons in the amygdala. Nat Neurosci 12: 1438-1443.

Zucchi R, Chiellini G, Scanlan TS, Grandy DK. 2006. Trace amine-associated receptors and their ligands. Br J Pharmacol 149: 967-978.

Received March 15, 2018; accepted in revised form June 21, 2018. 


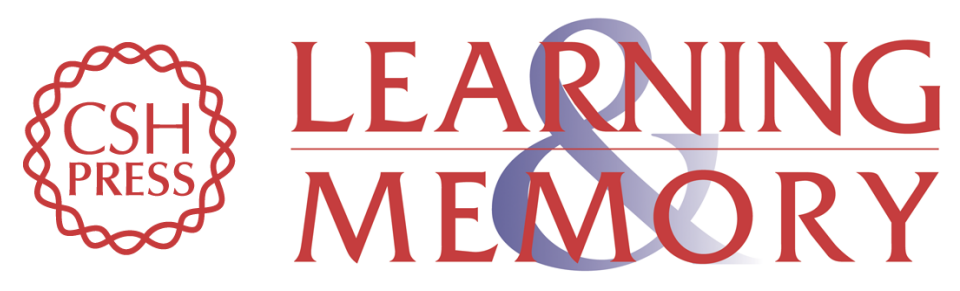

\section{The role of nonmuscle myosin II in polydrug memories and memory reconsolidation}

Sherri B. Briggs, Madalyn Hafenbreidel, Erica J. Young, et al.

Learn. Mem. 2018, 25:

Access the most recent version at doi:10.1101/Im.046763.117

\begin{aligned} & \hline References $\begin{array}{l}\text { This article cites } 65 \text { articles, } 13 \text { of which can be accessed free at: } \\ \text { http://learnmem.cshlp.org/content/25/9/391.full.html\#ref-list-1 }\end{array} \\ & \begin{aligned} \text { Creative } \\ \text { Commons } \\ \text { License }\end{aligned} \begin{array}{l}\text { This article is distributed exclusively by Cold Spring Harbor Laboratory Press for the } \\ \text { first } 12 \text { months after the full-issue publication date (see } \\ \text { http://learnmem.cshlp.org/site/misc/terms.xhtml). After } 12 \text { months, it is available under } \\ \text { a Creative Commons License (Attribution-NonCommercial } 4.0 \text { International), as } \\ \text { described at http://creativecommons.org/licenses/by-nc/4.0/. }\end{array} \\ & \begin{array}{c}\text { Receive free email alerts when new articles cite this article - sign up in the box at the } \\ \text { top right corner of the article or click here. }\end{array} \\ & \begin{array}{c}\text { Service } \\ \text { terting }\end{array}\end{aligned}$ 